\title{
Ozonioterapia em odontologia: E suas aplicabilidades
}

\author{
Ozoniotherapy in dentistry: And its applicabilities \\ Ozonioterapia en odontología: Y sus aplicabilidades
}

Recebido: 26/04/2021 | Revisado: 05/05/2021 | Aceito: 08/05/2021 | Publicado: 22/05/2021

\author{
Danilo Campos de Souza \\ ORCID: https://orcid.org/0000-0002-9220-569X \\ Faculdade Patos de Minas, Brasil \\ E-mail: danilocptr@gmail.com \\ Marcelo Dias Moreira de Assis Costa \\ ORCID: https://orcid.org/0000-0001-9148-3674 \\ Universidade Federal de Uberlândia, Brasil \\ E-mail: marcelodmac@yahoo.com.br \\ Fernando Nascimento \\ ORCID: https://orcid.org/0000-0003-3568-3887 \\ Faculdade Patos de Minas, Brasil \\ E-mail: fernando.nascimento@faculdadepatosdeminas.edu.br \\ Victor da Mota Martins \\ ORCID: https://orcid.org/0000-0001-6631-6161 \\ Faculdade Patos de Minas, Brasil \\ E-mail: victortag@hotmail.com \\ Lia Dietrich \\ ORCID: https://orcid.org/0000-0001-7887-8591 \\ Clínica privada, Brasil \\ E-mail: dietrichlia.ld@gmail.com
}

\begin{abstract}
Resumo
Este trabalho constou na revisão e estudo de vários artigos, os quais ajudaram a relatar o uso da terapia de ozônio em cada área da odontologia. Com o objetivo de demonstrar os diferentes meios e patologias tratadas por diferentes profissionais da área odontóloga, esta revisão conseguiu de maneira detalhada expor os pós e contras da terapia, obtendo um resultado de grande poder em seu uso pelos estudos. Concluindo ser uma das melhores alternativas aos que têm acesso, e que necessita de muitas pesquisas sobre para desmistificar esta opção mostrando aos céticos que não é conto de fadas e sim uma alternativa real.
\end{abstract}

Palavras-chave: Ozônio; Odontologia; Tratamento conservador.

\section{Abstract}

This work consisted of the review and study of several articles, which helped to report the use of ozone therapy in each area of dentistry. In order to demonstrate the different means and pathologies treated by different professionals in the dental field, this review managed to expose in detail the powders and cons of the therapy, obtaining a result of great power in its use by studies. Concluding that it is one of the best alternatives for those who have access and that it needs a lot of research to demystify this option, showing skeptics that it is not a fairy tale but a real alternative.

Keywords: Ozone; Dentistry; Conservative treatment.

\section{Resumen}

Este trabajo consistió en la revisión y estudio de varios artículos, que ayudaron a reportar el uso de la ozonoterapia en cada área de la odontología. Con el fin de demostrar los diferentes medios y patologías tratados por diferentes profesionales del campo dental, esta revisión logró exponer en detalle los polvos y contras de la terapia, obteniendo un resultado de gran potencia en su uso por estudios. Concluyendo que es una de las mejores alternativas para quienes tienen acceso, y que se necesita mucha investigación para desmitificar esta opción, mostrando a los escépticos que no es un cuento de hadas sino una alternativa real.

Palabras clave: Ozono; Odontología; Tratamiento conservador.

\section{Introdução}

O tratamento com a terapia de ozônio traz uma nova visão, cumpre-se com necessidades e demandas do público por não se adequa e é proposto aos pacientes que muitas vezes têm medo de "perfurar" e encontrar tratamento convencionais 
inaceitáveis (Kumar, Bhagawati, Tyagi, \& Kumar, 2014). Há uma mudança de paradigma na prática dental, e torna o atendimento odontológico mais eficaz (Kumar et al., 2014). Dessa forma, a terapia abriu novas perspectivas em modalidades de tratamento para pacientes de todas idades, aplicável em ampla gama de condições de difícil intra-oral e tecidos moles, tornase mais benéfico do que o convencional, pode ser facilmente encontrado em $90 \%$ de sua composição, à 20 ou $35 \mathrm{Km}$ de altitude de nossa atmosfera (Brasil, n.d.) (Kumar et al., 2014). Para tanto, obtêm-se através de descargas elétricas e sem dúvida deve ser manuseado por um profissional capacitado, pois possui diversas formas de utilizá-lo tais como técnicas e equipamentos específicos e diferentes no mercado. (Brasil, n.d.) (Bhateja, 2012). Desse modo, é ideal ter um aprofundamento no conhecimento da terapia (Bhateja, 2012). Necessita-se cautela por ser extremamente prejudicial quando não utilizado de forma correta, não dosado ou aplicado, enfim, quando não utilizado em suas devidas medidas pode ser altamente tóxico (Bhateja, 2012).

O gás pode ser aplicado puro ou misturado com outra substância (Bhateja, 2012). Na medicina pode-se adicionar ao sangue da pessoa, como também pode ser ozonizada água de osmose reversa, bidestilada ou soro, para que seja utilizada em protocolos de limpeza de feridas ou irrigação em procedimentos cirúrgicos (Bhateja, 2012). E de outra forma tem o óleo ozonizado que pode ser inserido sobre a mucosa, pele ou feridas (Bhateja, 2012).

Logo, todas as formas de administração para tratamento ou prevenção de afecções onde o gás ou a água ozonizada forem necessários, faz-se imprescindível o uso do aparelho gerador de ozônio (Bhateja, 2012). Apesar da terapia ter um grande valor positivo, existe contraindicações: gravidez, pacientes com infarto agudo do miocárdio, hipertireoidismo não controlado, intoxicação alcoólica ou problemas de coagulação, especialmente casos de favismo (Bhateja, 2012).

Portanto ozônio tem diversos efeitos benéficos: antimicrobiano, tem ações imonoestimulantes, analgésicas, antioxidantes, bioenergéticas, Biossintéticas e anti-hipóxicas, entretanto, na Odontologia, aplica-se com eficácia no tratamento da cicatrização de feridas, cárie dentária, líquen plano oral, gengivite e periodontite, halitose, osteonecrose da mandíbula, dor pós-cirúrgica, placa e biofilmes, tratamento do canal radicular, hipersensibilidade à dentina, distúrbios da articulação temporomandibular e clareamento dos dentes (Bhateja, 2012).

Este estudo tem grande importância devido ao pouco conhecimento, porém com a divulgação certa, pretende-se dizer, que na Odontologia, ainda são poucos profissionais que estão habilitados a exercer a ozonioterapia. Desse modo, ressalta-se com esta pesquisa fornecer informações sobre a aplicabilidade da ozonioterapia nas especialidades odontológicas, além de direcionar o profissional sobre as possibilidades e regras que norteiam a prática da ozonioterapia na Odontologia.

\section{Metodologia}

Este estudo seguiu uma abordagem qualitativa e realizou-se uma revisão de literatura com suporte metodológico de Metodologia da pesquisa científica (Pereira et al., 2018), assim analisando obras e pesquisas de autores que escreveram sobre ozonioterapia na vida do profissional dentista, com tudo separando suas abordagens por especializações reconhecidas pelo Conselho Federal de Odontologia - CFO. O futuro da terapia com ozônio deve se concentrar no estabelecimento de métodos seguros e bem definidos parâmetros de acordo com ensaios randomizados controlados para determinar as indicações precisas e diretrizes a fim de tratar várias patologias médicas e odontológicas. (Nogales, Ferrari, Kantorovich, \& Lage-Marques, 2008).

Utilizou-se 17 artigos para elaboração desse estudo, mais informações adquiridas por palestras e reportagens, por análise de artigos científicos, livros, revistas. Por via de livros em espécie da biblioteca e virtualmente por buscas em sites como: Google Acadêmico, Scielo, entre outros. Em um dos artigos uma pesquisa clínica envolvendo 11 pacientes Stübingeret et al, descreveu a eficácia local do ozônio em feridas intraorais infectadas após alta dose radioterapia. (Nogales et al., 2008).

As palavras-chave para realização da busca da pesquisa foram: Ozonioterapia, Odontologia, Ozônio, e ozone therapy 
in dentistry, ozone therapy clinical approaches, ozonotherapy benefits and malfunctions. Foram utilizados artigos científicos existentes na literatura nas bases de dados: SciELO, Lilacs, Google Acadêmico e PubMed.

\section{Revisão da Literatura}

O ozônio pode ser alterado por muitos processos relacionados a altitude, temperatura e poluição do ar (Bhateja, 2012). O ar atmosférico é composto de 71\% de nitrogênio, 28\% oxigênio, 1\% de outros gases inclusive o ozônio (Bhateja, 2012). Muitos pesquisadores já indicam para fins terapêuticos e por muito tempo é utilizado na medicina nativa (CAM) como uma das terapias mais milagrosas disponíveis no planeta no momento (Bhateja, 2012). Tendo como base em seu uso as propriedades antimicrobianas, anti-hipoxicas, analgésicas e imunoestimulantes do ozônio $\left(\mathrm{O}_{3}\right)$, sistemas biológicos (Bhateja, 2012). Pode ser terapêutico para grande variedade de doenças, inclusive infecções crônicas de poucos tratamentos disponíveis e eficazes (Bhateja, 2012).

Christian Friedrich shonbein em 1840, usou como termo OZONE que deriva da palavra grega Ozein de significado ODOR (Bhateja, 2012). Químico alemão que ficou conhecido como pai da terapia de ozônio (Bhateja, 2012). Em uma de suas pesquisas submeteu oxigênio a eletricidade e observou odor de matéria elétrica (Bhateja, 2012). Em 1857 Joachim Hansler, físico e médico alemão, juntamente com o médico alemão Hans Wolff, produziu o primeiro gerador de ozônio, assim pela primeira vez usou no campo da medicina, purificando sangue em tubos de ensaio por moléculas de O3 (Bhateja, 2012). Em 1893 na cidade de Ousbaden na Holanda tornou o primeiro lugar a utilizar agua estação de tratamento com ozônio (Bhateja, 2012). E nas duas guerras também utilizaram esse material para tratar feridas dos soldados nas trincheiras (Bhateja, 2012). Revisou-se seu uso e efeito no campo da medicina no início do século XX. Em 1950 Dr. EA Fisch foi o primeiro dentista a usar ozônio regularmente em sua clínica, fez inúmeros artigos sobre sua aplicação (Bhateja, 2012). Mariniak e Delarive mostraram que é um alotrópico em forma de oxigênio, mulliken e dewar esclareceram estrutura molecular (Bhateja, 2012).

\subsection{Utilização do Aparelho de Ozônio}

Existem três sistemas diferentes para gerar o gás do ozônio: Ultravioleta que é usado em saunas, ar, purificação e estética por produzir ozônio em baixa concentração. Tem-se como exemplo o sistema plasma frio usado para purificar a agua e o ar. E também o sistema de descarga Corona usado por médicos e dentistas, produzindo uma maior concentração de ozônio (Srikanth, Sathish, Venkatanaga, Harsha. et al., 2013).

Desta maneira, uma empresa no Canadá formulou uma unidade de ozônio com nome "CurOzone Inc.". Mais posteriormente foi fabricado sob licença e distribuído pela "KaVo Dental GmbH e Co" na Alemanha com o nome "HealOzone", com uso pioneiro pelo professor Lynch et al. Ele converte oxigênio em ozônio (Shiva \& Deepa, 2016).

Logo, o procedimento HealOzone consiste na inclusão de aplicação de gás ozônio, uso de remineralizadores, um kit de paciente e informações sobre Higiene oral. O aparelho HealOzone compreende um ar filtro, bomba de vácuo, gerador de ozônio, peça de mão equipado com um copo de silicone de vedação e uma mangueira flexível. Aproximadamente leva entre 20 e 120 segundos por dente para o procedimento, e após a aplicação, a superfície do dente é tratada com uma solução remineralizante (redutor) contendo fluoreto, cálcio, zinco, fosfato e xilitol dispensando em uma ampola de $2 \mathrm{ml}$. Portanto, aos pacientes são fornecidos um kit, que consiste em massa de dente, lavagem oral e spray oral, todos contendo flúor, cálcio, zinco, fosfato e xilitol e tem como objetivo melhorar o processo de remineralização. Aplicação HealOzone para o tratamento de lesões não-cavitadas é geralmente repetido 3 e 6 meses (Kumar et al., 2014).

Além disso, o OzoTop que é um sistema de distribuição de ozônio de fluxo livre descarga corona, mesa compacta e fácil de usar unidade. Pode ser usado em todos os casos em que é necessário um ponto de desinfecção no local, incluindo 
periodontologia, endodontologia, restauradora, implantologia, úlceras aftosas / herpes, gerodontologia (dentaduras) e materiais de impressão. O sistema utiliza o ambiente que é filtrado e seco antes de passar uma cerâmica placa onde é aplicada alta tensão e o ozônio é produzido. A sucção de alto volume é necessária pois é um sistema aberto (Kumar et al., 2014).

O equipamento gerador de ozônio desenvolve com uma abertura do sistema ou com sistema de sucção selado e pelo sistema por inalação contém evidências de efeitos adversos o sistema de sucção é geralmente usado. A água ozonizada é uma alternativa mais segura ao ozônio gasoso, pode ser usada como enxaguante bucal ou ingerida para matar fungos, bactérias e vírus, para vários problemas como halitose ou doença gengival. O óleo ozonizado pode ser eficiente e traz por fim uma maior permeação. Pode ser também subdivido em duas formas de aplicação: Formas sistêmicas que consiste em terapia Auto Hemo Maior (MAH) como extracorpóreo tratamento sanguíneo com $\mathrm{O}_{3}$ e reinfusão de sangue, insuflação retal da mistura de $\mathrm{O}_{3}$ e $\mathrm{O}_{2}$, terapia auto-hemo menor como injeção intramuscular de sangue ativado. Tendo mais opção as formas tópicas que consiste em aplicação transcutânea de gás ozônio em ambiente herméticos e tampas de plástico resistentes ao ozônio, água ozonizada sob uma forma de spray ou compressa, insuflação retal de $\mathrm{O}_{3}$ e $\mathrm{O}_{2}$, injeções intra-articulares, injeções intramusculares, azeite ozonizado (Bhateja, 2012; Suh et al., 2019).

\section{2 Áreas da odontologia e formas de utilização do ozônio em cada}

Tabela 1 - Aplicabilidade Ozônio Especialidades Odontológicas.

\begin{tabular}{|c|c|c|c|c|}
\hline Especialidade & Aplicabilidade & $\begin{array}{c}\text { Forma } \\
\text { administração }\end{array}$ & Ação & Referências \\
\hline $\begin{array}{c}\text { Cirurgia } \\
\text { Bucomaxilofacial }\end{array}$ & $\begin{array}{l}\text { - Auxiliar ferida epitelial } \\
\text { - Alta taxa de cura. } \\
\text { - Cura sem necessidade de medicação } \\
\text { sistêmica. } \\
\text { - Tratamento de alveolite } \\
\text { - Pós extração dentária } \\
\text { - Complicações pós-extração } \\
\text { - Alvéolo seco. (Bhateja, 2012). } \\
\text { - Irrigante } \\
\text { - Suturas (Srikanth et al., 2013). }\end{array}$ & Água / Óleo & $\begin{array}{l}\text { Bactericida / fungicida / } \\
\text { antisséptico / analgésico / } \\
\text { antioxidante / anti- } \\
\text { inflamatório / Cicatrizante }\end{array}$ & $\begin{array}{c}\text { (Bhateja, 2012) / } \\
\text { (Srikanth et al., } \\
\text { 2013) }\end{array}$ \\
\hline Odontopediatria & $\begin{array}{l}\text { - Candidíase oral (popularmente conhecido } \\
\text { por “Sapinho") } \\
\text { - Cárie } \\
\text { - Líquen plano } \\
\text { - Limpeza área afetada } \\
\text { - Desinfetar mucosa oral } \\
\text { - Profilaxia / Adequação } \\
\text { - Prevenção de cárie } \\
\text { - Restauração de cavitações abertas junto com } \\
\text { medidas conservadoras } \\
\text { - Tratamento de feridas infectadas } \\
\text { - Processo inflamatório } \\
\text { - Prevenção de cárie em fossas / fissuras } \\
\text { - Desinfecções em endodontia }\end{array}$ & $\begin{array}{l}\text { Água / spray / } \\
\text { jato de água }\end{array}$ & Bactericida / fungicida & $\begin{array}{c}\text { (Bhateja, 2012) / } \\
\text { (Shiva \& Deepa, } \\
\text { 2016) / (Suh et } \\
\text { al., 2019) }\end{array}$ \\
\hline Endodontia & $\begin{array}{l}\text { - Clareador endogeno } \\
\text { - Alivio rápido e imediato de sensibilidade na } \\
\text { raiz } \\
\text { - Dessensibilização da dentina dura por um } \\
\text { longo tempo } \\
\text { - Impede penetração de cálcio e flúor nos } \\
\text { túbulos dentinários. (Bhateja, 2012). } \\
\text { - Fechamento não cirúrgico } \\
\text { - Nenhum efeito colateral ou prejuízo. (Alves, } \\
\text { 2017) }\end{array}$ & Spray / Gás & $\begin{array}{l}\text { Anti-inflamatório / } \\
\text { dessensibilizante / } \\
\text { bactericida / Clareador }\end{array}$ & $\begin{array}{c}\text { (Bhateja, 2012) / } \\
\text { (Alves, 2017) }\end{array}$ \\
\hline Periodontia & $\begin{array}{l}\text { - Pode substituir o desbridamento mecânico. } \\
\text { - Inibir fortemente a formação de placa, - } \\
\text { Inibe número de patógenos subgengivais. } \\
\text { - Inibe bactérias Gram-negativas. } \\
\text { - Pode ser eficiente para abscesso periodontal } \\
\text { sem exsudação. }\end{array}$ & $\begin{array}{l}\text { Água / Gás / } \\
\text { Óleo }\end{array}$ & Antioxidante / Bactericida & $\begin{array}{l}\text { (Bhateja, 2012) / } \\
\text { (Shoukheba \& } \\
\text { Ali, 2014) / } \\
\text { (Habashneh et } \\
\text { al., 2014) / (Kaul } \\
\text { \& Shilpa, 2014) }\end{array}$ \\
\hline
\end{tabular}


Research, Society and Development, v. 10, n. 6, e11410615517, 2021

(CC BY 4.0) | ISSN 2525-3409 | DOI: http://dx.doi.org/10.33448/rsd-v10i6.15517

\begin{tabular}{|c|c|c|c|c|}
\hline & $\begin{array}{l}\text { - Doenças crônicas. } \\
\text { - Doenças gengivais e periodontais. } \\
\text { - Mudanças subjetivas. } \\
\text { - Periodontite agressiva. } \\
\text { - Odontite. } \\
\text { - Placas subgengivais. } \\
\text { - Descamação e aplainamento radicular } \\
\text { - Efeitos positivos contra cândida albicans. } \\
\text { - Destruição de bactérias. (Bhateja, 2012) } \\
\text { (Shoukhheba \& Ali, 2014) (Huth et al., 2011) } \\
\text { (Habashneh et al., 2014) (Kaul \& Shilpa, 2014). }\end{array}$ & & & \\
\hline Odontogeriatria & $\begin{array}{l}\text { - Quadros avançados de doenças periodontais } \\
\text { - Cândida-albicans } \\
\text { - Bochechos, gargarejos } \\
\text { - Ingestão da água para halitose } \\
\text { - Xerostomia } \\
\text { - Sialosquese } \\
\text { - Desinfecção de próteses. }\end{array}$ & Água & $\begin{array}{l}\text { Bactericida / fungicida / } \\
\text { antisséptico / analgésico / } \\
\text { antioxidante / anti- } \\
\text { inflamatório }\end{array}$ & \\
\hline Prótese Dentária & $\begin{array}{l}\text { - E potente contra Staphylococcus aureus } \\
\text { - Vírus resistentes à meticilina } \\
\text { - É potencial na limpeza de próteses. (Bhateja, } \\
\text { 2012). } \\
\text { - Controle de estomatite protética } \\
\text { - Causa pequena alteração na liga Au-Cu-Ag- } \\
\text { Pd em termos de refletância. } \\
\text { - Resistente à meticilina Staphylococcus } \\
\text { aureus e Escherichia coli T1 fago vírus bactéria } \\
\text { - O ozônio gasoso em relação a próteses foi } \\
\text { mais eficaz que a água ozonizada. (Kumar et } \\
\text { al., 2014). }\end{array}$ & $\begin{array}{l}\text { Gás / Água / } \\
\text { Óleo }\end{array}$ & Bactericida / fungicida & $\begin{array}{c}\text { (Bhateja, 2012) / } \\
\text { (Kumar et al., } \\
\text { 2014) }\end{array}$ \\
\hline Implantodontia & $\begin{array}{l}\text { - Irrigação } \\
\text { - Na área tratada o paciente pode ser } \\
\text { instruído a aplicar óleo ozonizado 3-4 vezes / } \\
\text { dia. (Srikanth et al., 2013). } \\
\text { - Gás borbulhado no Alvéolo externo. } \\
\text { - Reduz porcentagem de infecção. (Shete et } \\
\text { al., 2016) }\end{array}$ & $\begin{array}{l}\text { Gás / Óleo / } \\
\text { Água }\end{array}$ & $\begin{array}{l}\text { Antimicrobiano / } \\
\text { Antisséptico }\end{array}$ & $\begin{array}{l}\text { (Srikanth et al., } \\
\text { 2013) / (Shete } \\
\text { et al., 2016) }\end{array}$ \\
\hline Ortodontia & $\begin{array}{l}\text { - Redução de inflamação subgengival } \\
\text { - Placa retentiva } \\
\text { - Irrigação subgengival }\end{array}$ & Água & Anti-inflamatório & $\begin{array}{l}\text { (Kaul \& Shilpa, } \\
\text { 2014) }\end{array}$ \\
\hline Dentística & $\begin{array}{l}\text { - Diminuição de desgaste do remanescente } \\
\text { dentário. } \\
\text { - Confortável para o paciente. } \\
\text { - Mais econômico } \\
\text { - Simplicidade no tratamento } \\
\text { - Evita de enfraquecer o dente com excessivo } \\
\text { desgaste } \\
\text { - Usa menos material obturador } \\
\text { - Estudo constou que o ozônio não interfere } \\
\text { nas propriedades adesivas. (Bhateja, 2012). } \\
\text { - Amplamente estudado } \\
\text { - Fossas e cárie de fissura } \\
\text { - Cárie radicular } \\
\text { - Cárie Inter proximal. } \\
\text { - Oxida o ácido pirúvico } \\
\text { - Infusão de ozônio na dentina não cariosa } \\
\text { evita a formação de biofilme } \\
\text { - Matar diferentes concentrações de S. } \\
\text { mutans, Lactobacillus casei e Actinomyces } \\
\text { naeslundii. } \\
\text { - Oxida o enxofre volátil } \\
\text { - Evita o mau cheiro associado com cárie de } \\
\text { raiz. (Kumar et al., 2014). } \\
\text { - A halitose (mal hálito crônico) pode diminuir. } \\
\text { - Clareamento de dentes. (Suh et al., 2019) }\end{array}$ & Água / Gás & Antioxidante & $\begin{array}{l}\text { (Bhateja, 2012) / } \\
\text { (Kumar et al., } \\
\text { 2014) / (Suh et } \\
\text { al., 2019) / } \\
\text { (Shete et al., } \\
\text { 2016) / (Huth et } \\
\text { al., 2011) / (Kaul } \\
\text { \& Shilpa, 2014) }\end{array}$ \\
\hline $\begin{array}{c}\text { Harmonização } \\
\text { Orofacial }\end{array}$ & $\begin{array}{l}\text { - Cirurgias e ao lado das plásticas } \\
\text { - Pode ser um potente condicionador } \\
\text { sistêmico } \\
\text { - Imunomodulador } \\
\text { - Asséptico } \\
\text { - Transcirurgico }\end{array}$ & $\begin{array}{l}\text { Gás / Água / } \\
\text { Óleo / Spray } \\
\text { espuma } \\
\text { ozonificada }\end{array}$ & $\begin{array}{l}\text { Desinfetante / oxidante / } \\
\text { anti-algico / asséptico }\end{array}$ & $\begin{array}{c}\text { (Libório, 2020) / } \\
\text { (Nogales et al., } \\
\text { 2018) }\end{array}$ \\
\hline
\end{tabular}


Research, Society and Development, v. 10, n. 6, e11410615517, 2021

(CC BY 4.0) | ISSN 2525-3409 | DOI: http://dx.doi.org/10.33448/rsd-v10i6.15517

\begin{tabular}{|c|c|c|c|c|}
\hline & $\begin{array}{l}\text { - Modulador inflamatório } \\
\text { - Controle álgico } \\
\text { - Baixa citoxicidade. } \\
\text { - Melhor pós-operatório, com menos dor, } \\
\text { menos chances de respostas inflamatórias. } \\
\text { - Bichectomia } \\
\text { - Trabalha junto com as necessidades que } \\
\text { aquele tecido está distribuindo, não } \\
\text { ausentando a infecção mais sim modulando-a. } \\
\text { - Modulação fisiológica, bioestimulação } \\
\text { - Aceleração da cura. } \\
\text { - Associação com auriculoterapia, } \\
\text { - Lipoaspiração } \\
\text { - Alectomia } \\
\text { - Blefaroplastia } \\
\text { - Canto de olho (pé de galinha) } \\
\text { - Torno da boca } \\
\text { - Cirurgia de retirada de papada. (Libório, } \\
\text { 2020). } \\
\text { - Auto-hemoterapia } \\
\text { - Reinfusão intravenosa do sangue tratado do } \\
\text { paciente } \\
\text { - Distúrbios circulatórios arteriais } \\
\text { - Infecções e para artrite reumática. } \\
\text { - Auto-hemoterapia menor } \\
\text { - Alergias } \\
\text { - Acne } \\
\text { - Furunculose } \\
\text { - Estimulação geral do sistema imunológico. } \\
\text { (Nogales et al., 2018). }\end{array}$ & & & \\
\hline Estomatologia & $\begin{array}{l}\text { - Previne cárie } \\
\text { - Redução de bolsas periodontais } \\
\text { - Prevene periodontite e gengivite. } \\
\text { - Lavagem de próteses com a água ozonizada } \\
\text { - Lesão da candidíase. } \\
\text { - Lesões de tecidos moles } \\
\text { - Herpes } \\
\text { - Aftas } \\
\text { - Úlceras de próteses removíveis } \\
\text { - Cortes } \\
\text { - Queilite } \\
\text { - Candidíase } \\
\text { - Cistos } \\
\text { - Feridas traumáticas } \\
\text { - Cicatrização das lesões. (Kumar et al., 2014). } \\
\text { - Aumento da cicatrização de feridas após } \\
\text { uma radioterapia de alta dose. } \\
\text {-Substituição tratamento com esteroides. (Suh } \\
\text { et al., 2019). } \\
\text { - Efeitos de imunoativação } \\
\text { - Reinfusão intravenosa de sangue } \\
\text { extracorpóreo tratado por gás, pode amenizar } \\
\text { carcinomas. } \\
\text { - Herpes labiale } \\
\text { - Osteomielite mandibular. (Nogales et al., } \\
\text { 2008). }\end{array}$ & $\begin{array}{l}\text { Água / Óleo / } \\
\text { Gás }\end{array}$ & $\begin{array}{l}\text { Desinfetante / oxidante / } \\
\text { anti-algico / asséptico }\end{array}$ & $\begin{array}{l}\text { (Kumar et al., } \\
\text { 2014) / (Suh et } \\
\text { al., 2019) / } \\
\text { (Nogales et al., } \\
\text { 2008) }\end{array}$ \\
\hline Odontologia Legal & $\begin{array}{l}\text { Como esta área da odontologia trabalha no } \\
\text { campo da criminalística e identificação de } \\
\text { corpos, não se usa a terapia de ozônio! }\end{array}$ & & & \\
\hline $\begin{array}{l}\text { Odontologia do } \\
\text { Trabalho }\end{array}$ & $\begin{array}{l}\text { Está é outra especialidade que não tem um } \\
\text { método especifico para interagir com a } \\
\text { terapia do ozônio, a especialidade visa em } \\
\text { cuidar de funcionários de uma certa empresa, } \\
\text { ou de algum setor que seu ambiente gere } \\
\text { riscos à saúde bucal, assim fica subentendido } \\
\text { que todos os procedimentos que um clinico } \\
\text { geral realiza e foram citados sua abordagem } \\
\text { dentro do ozônio anteriormente, podem ser } \\
\text { replicadas nesta especialidade de tal maneira. }\end{array}$ & & & \\
\hline $\begin{array}{c}\text { Patologia Oral e } \\
\text { Maxilofacial }\end{array}$ & $\begin{array}{l}\text { - Feridas epiteliais resposta cicatrizante na } \\
\text { mucosa oral. }\end{array}$ & Água / Óleo & $\begin{array}{c}\text { Bactericida / fungicida / } \\
\text { antisséptico / analgésico / }\end{array}$ & $\begin{array}{c}\text { (Bhateja, 2012) / } \\
\text { (Kumar et al., }\end{array}$ \\
\hline
\end{tabular}


Research, Society and Development, v. 10, n. 6, e11410615517, 2021

(CC BY 4.0) | ISSN 2525-3409 | DOI: http://dx.doi.org/10.33448/rsd-v10i6.15517

\begin{tabular}{|c|c|c|c|c|}
\hline & $\begin{array}{l}\text { - Pós-operatório. } \\
\text { - Acelera o processo fisiológico taxa de cura. } \\
\text { - Alveolite. } \\
\text { - Pós extração dentaria e em complicações } \\
\text { pós-cirurgia } \\
\text { - Alvéolo seco (Bhateja, 2012) } \\
\text { - - Tratamento da osteomielite refratária na } \\
\text { cabeça e pescoço } \\
\text { - Tem uma influência positiva no metabolismo } \\
\text { ósseo e no processo reparador do osso. } \\
\text { - Ozônio no manejo da necrose óssea e em } \\
\text { locais de extração. } \\
\text { - Pode estimular células proliferação e } \\
\text { cicatrização de tecidos moles. } \\
\text { - Alveolite tem cura acelerada } \\
\text { - Elimina alvéolos e dor pós extração. (Kumar } \\
\text { et al., 2014) } \\
\text { - Osteonecrose da mandíbula } \\
\text { - Cirurgias com a junção do ozônio e o lazer } \\
\text { houve uma queda dos níveis de dores. (Suh et } \\
\text { al., 2019). } \\
\text { - Diminuição do uso de medicação pós- } \\
\text { operatória } \\
\text { - Injeção intra-articular de gás ozônio pode } \\
\text { tratar distúrbios internos da articulação. (Suh } \\
\text { et al., 2019). }\end{array}$ & & $\begin{array}{l}\text { antioxidante / anti- } \\
\text { inflamatório / Cicatrizante }\end{array}$ & $\begin{array}{l}\text { 2014) / (Suh et } \\
\text { al., 2019) / } \\
\text { (Shete et al., } \\
\text { 2016) }\end{array}$ \\
\hline $\begin{array}{l}\text { Radiologia } \\
\text { Odontológica e } \\
\text { Imaginologia }\end{array}$ & $\begin{array}{l}\text { Como essa especialidade tem como objetivo } \\
\text { de realizar exames e diagnosticar radiografias } \\
\text { e outros pela imagem, não se inclui a terapia } \\
\text { em tal. }\end{array}$ & & & \\
\hline $\begin{array}{l}\text { Odontologia em } \\
\text { Saúde Coletiva }\end{array}$ & $\begin{array}{l}\text { Como a saúde coletiva visa mais em prevenir, } \\
\text { em estudos e promoção da saúde o ozônio } \\
\text { pode ser abordado normalmente em } \\
\text { protocolos clínicos como citados a cima que } \\
\text { também fazem parte do dia a dia deste } \\
\text { especialista. }\end{array}$ & & & \\
\hline Acupuntura & $\begin{array}{l}\text { - Alivio dos trigger Points } \\
\text { - Efeitos analgésicos, fisiológicos e } \\
\text { terapêuticos } \\
\text { - Regride inflamação } \\
\text { - Fibromialgia } \\
\text { - Ansiedade } \\
\text { - Dor na coluna } \\
\text { - Coluna travada } \\
\text { - Tendinite } \\
\text { - Tenossinovite } \\
\text { - Enxaqueca } \\
\text { - Depressão } \\
\text { - Insônia } \\
\text { - Sequelas da covid-19. Podendo também } \\
\text { aumentar imunidade, aliviar dores. }\end{array}$ & Gás / óleo & $\begin{array}{c}\text { Analgésico / antisséptico / } \\
\text { antioxidante }\end{array}$ & (Landim, 2020) \\
\hline Homeopatia & $\begin{array}{l}\text { Como esta especialidade trabalha em foco da } \\
\text { prevenção, diagnóstico, prognóstico e o } \\
\text { tratamento das doenças próprias da boca e } \\
\text { suas estruturas anexas. Também no controle } \\
\text { dos problemas orais e na melhoria da } \\
\text { qualidade de vida dos pacientes. E é adjunta } \\
\text { sempre em parceria com outra especialidade } \\
\text { a terapia de ozônio pode ser incluída, } \\
\text { abordada e utilizada assim como citado nas } \\
\text { especialidades anteriores. }\end{array}$ & $\begin{array}{l}\text { Água / gás / } \\
\text { spray / óleo }\end{array}$ & $\begin{array}{l}\text { Bactericida / fungicida / } \\
\text { antisséptico / analgésico / } \\
\text { antioxidante / anti- } \\
\text { inflamatório / Cicatrizante }\end{array}$ & \\
\hline $\begin{array}{l}\text { Odontologia do } \\
\text { Esporte }\end{array}$ & $\begin{array}{l}\text { Como esta especialidade visa em objetivo de } \\
\text { investigar, prevenir, tratar, reabilitar e } \\
\text { compreender a influência das doenças da } \\
\text { cavidade oral no desempenho dos atletas, } \\
\text { entende-se que a terapia do ozônio assim } \\
\text { como em outras especialidades acima segue } \\
\text { as mesmas indicações, recomendações e } \\
\text { utilização da terapia igual as demais } \\
\text { especialidades como dentistica, prótese, } \\
\text { endodontia, entre outras. }\end{array}$ & $\begin{array}{l}\text { Água / gás / } \\
\text { spray / óleo }\end{array}$ & $\begin{array}{l}\text { Bactericida / fungicida / } \\
\text { antisséptico / analgésico / } \\
\text { antioxidante / anti- } \\
\text { inflamatório / Cicatrizante }\end{array}$ & \\
\hline
\end{tabular}




\begin{tabular}{|c|c|c|c|c|}
\hline $\begin{array}{l}\text { Ortopedia Facial dos } \\
\text { Maxilares }\end{array}$ & $\begin{array}{l}\text { Não há muito material falando sobre essa } \\
\text { especialidade, mais dentro dela há ortopedia } \\
\text { mecânica que trabalha com forças mais } \\
\text { intensas movendo ossos, e a ortopedia } \\
\text { funcional que trabalha em conjunto com } \\
\text { forças fisiológicas dos músculos, sendo menos } \\
\text { invasiva, assim como a ortodontia ambas } \\
\text { também trabalham com auxílio de aparelhos } \\
\text { que estimulam a locomoção, } \\
\text { reposicionamento de ossos e dentes } \\
\text { colocando a arcada em equilíbrio, harmonia, } \\
\text { respeitando funcionalidades e oclusão, como } \\
\text { a ortopedia não é tão diferente da ortodontia } \\
\text { e não foi achado artigos que falam } \\
\text { especificamente desta área, suponho que da } \\
\text { mesma forma que o ozônio é abordado na } \\
\text { ortodontia ele pode ser utilizado em } \\
\text { ortopedia aos profissionais que manifestem } \\
\text { interesse. }\end{array}$ & Água & Anti-inflamatório & $\begin{array}{c}\text { (Kaul \& Shilpa, } \\
\text { 2014) }\end{array}$ \\
\hline $\begin{array}{c}\text { Disfunção } \\
\text { Temporomandibular } \\
\text { e Dor Orofacial }\end{array}$ & $\begin{array}{l}\text { Nesta especialidade visa em adquirir uma } \\
\text { melhor compreensão no diagnóstico e no } \\
\text { tratamento de dores na região oral e em } \\
\text { estruturas relacionadas, em descritos mais } \\
\text { atrás foi relatado que o ozônio é um potente } \\
\text { anti-álgico, podendo ser usado por injeção via } \\
\text { intravenosa na forma de gás, no caso. }\end{array}$ & Gás & Anti-algico & \\
\hline $\begin{array}{l}\text { Odontologia para } \\
\text { Pacientes Especiais }\end{array}$ & $\begin{array}{l}\text { - Resposta melhor aos níveis de dor aliviando } \\
\text { assim a ansiedade do paciente } \\
\text { - Anula a incidência de ácaros, fungos e } \\
\text { bactérias em geral } \\
\text { - Proporciona defesa total contra agentes } \\
\text { poluentes } \\
\text { - Alivia as vias aéreas dos respiradores bucais } \\
\text { - Pode enxaguar boca de pacientes com } \\
\text { dificuldade motoras } \\
\text { - Prevenção de cáries, e outas doenças bucais } \\
\text { - Corrige estresse oxidativo } \\
\text { - Recuperação funcional de áreas } \\
\text { comprometidas por doenças crônicas } \\
\text { - Aprimora o metabolismo basal } \\
\text { - Aumenta a glutationa reduzida } \\
\text { - Regula as enzimas antioxidantes } \\
\text { - Ativa o sistema imunológico } \\
\text { - Aumenta a liberação de fatores de } \\
\text { crescimento } \\
\text { - Praticidade no procedimento, reduzindo } \\
\text { estresse no paciente especial. (Ozônio, Saúde } \\
\text { em geral, 2019) (Ozônio, Ozonioterapia, Saúde } \\
\text { em geral, 2020) (Asma, Bronquite, Enfisema, } \\
\text { Ozônioterapia, 2020). }\end{array}$ & $\begin{array}{c}\text { Gás / Óleo / } \\
\text { Água / Ar }\end{array}$ & $\begin{array}{c}\text { Bactericida / fungicida / } \\
\text { antisséptico / analgésico / } \\
\text { antioxidante / anti- } \\
\text { inflamatório / Cicatrizante } \\
\text { / Anti-álgico }\end{array}$ & $\begin{array}{c} \\
\\
\\
\text { (Ozônio, Saúde } \\
\text { em geral, 2019) } \\
\text { / (Ozônio, } \\
\text { Ozonioterapia, } \\
\text { Saúde em geral, } \\
\text { 2020) / (Asma, } \\
\text { Bronquite, } \\
\text { Enfisema, } \\
\text { Ozônioterapia, } \\
\text { 2020) }\end{array}$ \\
\hline $\begin{array}{c}\text { Prótese } \\
\text { Bucomaxilofacial }\end{array}$ & $\begin{array}{l}\text { Este especialista cuida da recuperação de } \\
\text { coroas dentais perdidas e reparação dos } \\
\text { espaços das extrações, de acordo com o } \\
\text { estudado o ozônio gasoso pode ser útil nesta } \\
\text { área para limpeza, higienização das coroas e o } \\
\text { gás pode ser útil para a reparação dos espaços } \\
\text { decorrentes de extrações. }\end{array}$ & Água / Gás & $\begin{array}{l}\text { Bactericida / fungicida / } \\
\text { antisséptico / anti- } \\
\text { inflamatório / Cicatrizante }\end{array}$ & \\
\hline
\end{tabular}

Fonte: Autores.

O ozônio na odontologia pode ser utilizado por infusão no osso maxilar infectado (cavitação). Infusão na articulação temporomandibular para o tratamento da dor e inflamação, usa-se também como solução irrigadora durante uma nova terapia de canal radicular como desinfetante na região do dente envolvido. Ressalta-se ainda, que a terapia adjuvante com uso de azeitona ozonizada óleo para doença periodontal. Tem as formas sistêmicas de aplicação que são: Terapia Auto Hemo Maior (MAH) como extracorpórea, tratamento sanguíneo com $\mathrm{O}_{2}$ e reinfusão de sangue, insuflação retal da mistura de $\mathrm{O}_{3}$ e $\mathrm{O}_{2}$, terapia auto-hemo menor como injeção intramuscular de sangue ativado. Tem as formas tópicas de aplicação que são: 
Aplicação transcutânea de gás ozônio em ambientes herméticos e tampas de plástico resistentes ao ozônio, água ozonizada sob uma forma de spray ou compressa, insuflação retal de $\mathrm{O}_{3}$ e $\mathrm{O}_{2}$, injeções intra-articulares, injeções intramusculares, azeite ozonizado. Enfim à aplicação pode ser por vários meios, como gás, água e óleo (Bhateja, 2012). Sabendo que uma injeção intravenosa não deve ser usada para administrar ozônio por quê pode se formar uma embolia aérea (Suh et al., 2019).

Para tanto, a ozonioterapia na odontologia está sendo mais benéfico que as modalidades terapêuticas convencionais, a profissão está mudando, agora usando ciências modernas para praticar odontologia. Desse modo, permite-se um tratamento mini invasivo e mais conservador no elemento dentário e o principal uso dessa terapia na odontologia, é suas propriedades antimicrobianas. É provado ser eficaz contra bactérias Gram-Negativas, Gram-Positivas, vírus e fungos (Bhateja, 2012). Foi montado uma tabela para mostrar que no ramo de trabalho do profissional cirurgião dentista o ozônio pode ter grande papel em várias modalidades de tratamento.

\subsection{Pontos Negativos e Positivos da Terapia}

Os pontos negativos são demarcados por ser extremamente perigoso para o trato respiratório, pois mistura-se com monóxido de carbono (CO), dióxido de nitrogênio (NO2), e alguns ácidos. Sendo assim, o ozônio é controvertido na literatura, provoca lacrimejamento, irritação no trato respiratório superior, rinite, tosse, náuseas, aumento progressivo de dispneia são alguns dos efeitos da exposição ao ozônio pela via inalatória (Nagib, 2006; Nesi, 2018).

Destaca-se ainda, que a inalação de ozônio pode ser tóxica para o sistema pulmonar e outros órgãos, isto é complicações causadas pelo ozônio. A terapia não é frequente em 0,0007 por aplicação e efeitos colaterais são irritação das vias aéreas superiores, rinite, tosse, dor de cabeça, náusea ocasional, vômito, falta respiração, inchaço dos vasos sanguíneos, má circulação, problemas no coração e epífora. Inalação prolongada de ozônio pode ser prejudicial para os pulmões e outros órgãos, mas doses bem calibradas podem ser utilizadas terapeuticamente em várias condições sem toxicidade ou efeitos adversos. Assim, as sociedades médicas de ozônio proibiam injeções intravenosas de gás ozônio devido ao risco de ar embolia e em caso de toxidade o paciente deve ser colocado em posição supina inalar oxigênio úmido, ser tratado com vitamina $\mathrm{E}$, ácido ascórbico e n-acetilcisteínas, pois tem como efeitos colaterais a injeção intravenosa direta de aumentos de ozônio risco de embolia. Sensação de queimação nos olhos. Dificuldade para respirar. Por fim, foi relatado que o ozônio causa certo efeitos como rinite, náusea ocasional, vômitos, inchaço dos vasos sanguíneos, má circulação, problemas cardíacos, vias respiratórias irritação e às vezes derrame (Kumar et al., 2014).

Ressalta-se que pode ser prejudicial ainda na gravidez, pessoas com deficiência de glicose-6-fosfato-desidrogenase (favismo), em pessoas com hipertireoidismo, com grave de anemia, túmulo de miastenia, intoxicação aguda por álcool, infarto do miocárdio recente, hemorragia de qualquer órgão, alergia ao ozônio (Kumar et al., 2014).

Toxicidade por ozônio se o nível aumentar em 0,0007\% por inscrever. Instabilidade não está prontamente disponível (Srikanth et al., 2013).

Tem como efeitos colaterais: Epífora, rinite, tosse, dor de cabeça, náusea e vômito. (Suh et al., 2019).

A maioria dos terapeutas tem uma concepção errônea sobre o ozônio, assim tornando sua atividade obscura, não sendo devidamente exercida ou reconhecida. E ás vezes, profissionais não sabem nem como ele age no sangue e em fluidos biológicos. Um grande problema de doenças crônicas que na medicina oficial tende a tratar os sintomas em vez das causas da doença. (Bocci, 2004).

O ozônio pode ser totalmente eficaz ou toxico, depende apenas da dosagem, que diferencia de pessoa para pessoa (Huth et al., 2011).

Contudo, é importante dizer, que possui mais pontos positivos do que negativos, pois serão citados agora alguns deles, 
desse modo esta pesquisa destaca sua eficácia, tem como características uma tendência de absorver perigosos raios ultravioleta na estratosfera, prevenindo de câncer de pele. Ele tem potentes efeitos antimicrobianos (bactericidas, viricidas e fungicidas), é imunoestimulante, anti-hipóxico / desintoxicante, bioenergética, biosintético, síntese de substâncias biologicamente ativas e analgésico. Em seu mecanismo de ação pode causar danos à membrana citoplasmática, oxidação do conteúdo intracelular especifico para célula microbiana, ser eficaz na cepa resistiva a antibióticos, ativa o sistema imunológico celular e humoral, prolifera células de imunocomplemento, sintetiza imunoglobulinas, aumentar a atividade de fagocitose, ativa oxidantes biológicos, ativa processo aeróbico (ciclo de Krebs, glicólise, oxidação de ácidos graxos), ativa síntese de proteínas, aumenta metabolismo celular (ribossomo, mitocôndrias), as substancias são biologicamente ativas, síntese de interleucinas, leucotrienos, imunoglobulinas e prostaglandinas (Kaul \& Shilpa, 2014).

\subsection{Legislações na Odontologia}

Conforme resolução 166/2015 da CFO; Art. $1^{\circ}$. O ozônio, produzido a partir do oxigênio puro em concentrações precisas de acordo com a janela terapêutica, pode ser usado na odontologia, ganhando nome como Ozonioterapia. Devido sua eficácia em reduzir infecções, bactérias e fungos, o ozônio fica proposto na odontologia como uma alternativa antisséptica.

No art. $2^{\circ}$. Fica esclarecido que o cirurgião dentista deve ser apto a manusear a terapia, fazer diagnósticos personalizados de acordo com a condição bucal de cada paciente, e ainda neste artigo é citado as áreas que o profissional pode correlacionar a terapia que é áreas que incluem dentistica, periodontia, endodontias, cirurgias, dores e disfunções da ATM, e necroses dos maxilares.

Conclui-se no artigo 3 dizendo que para o profissional ganhar habilitação em ozonioterapia, deve-se está registrado no Conselho Regional de Odontologia (CRO) e ter concluído formação de no mínimo 32 horas em curso de Ozonioterapia para cirurgião-dentista, ministrado por uma instituição de ensino superior reconhecido pelo CFO. (Conselho Federal de Odontologia, 2015).

\section{Considerações Finais}

Fica evidente, neste estudo, que a terapia é uma das melhores, com grande potencial, poucos efeitos adversos e podendo ser uma alternativa a tratamentos antes ditos como perdidos, melhorando prognósticos. Com essa ferramenta de uso secundário, pode-se revolucionar toda indústria farmacêutica e todos cuidados clínicos, não se sabe ao certo o real poder do ozônio, mais o que já se pode ver é que ele pode fazer muito mais na qualidade da saúde e na vida do indivíduo do que podemos imaginar. A real dificuldade do ozônio está em suas dosagens que não tem um padrão de indivíduo para indivíduo muda tudo, e ao extrapolar pode ser extremamente toxico. Em futuros estudos seria bom em cada especialidade entrar mais a fundo, explorar mais artigos ou até mesmo realizar uma revisão de caso.

\section{Referências}

Al-Omiri, M. K., Alhijawi, M., AlZarea, B. K., Hassan, R. A., \& Lynch, E. (2016). Ozone treatment of recurrent aphthous stomatitis: a double blinded study. Scientific Reports. 6 (1), 11-21. http://dx.doi.org/10.1038/srep27772.

Alves W. N. S. (2017). Ozonioterapia em caso de osteonecrose avançada associada a bisfosfonato oral em paciente com osteoporose: relato de caso. Trabalho de Conclusão de Curso em Odontologia. Brasília: Faculdade de Ciências da Saúde da Universidade de Brasília. https://bdm.unb.br/bitstream/10483/18006/1/2017_WinnieNascimentoAlves_tcc.pdf.

Asma, Bronquite, Enfisema, Ozônioterapia. (2020). Entenda mais sobre asma, bronquite e enfisema. Dr. Ozônio. https://drozonio3.com.br/2020/01/22/entenda-mais-sobre-asma-bronquite-e-enfisema/.

Bhateja. (2012). The miraculous healing therapy - "Ozone therapy" in dentistry. Indian Journal Of Dentistry. 3 (2), 150-55. http://dx.doi.org/10.1016/j.ijd.2012.04.004. 
Bocci, V. (2004). How Ozone Acts and how it Exerts Therapeutic Effects. In: Lynch, Edward (Ed.). Ozone: The Revolution in Dentristtry. Londres: Quintessence Books. 1. 15-22. Tradução livre: Edgar F. Müller.

Brasil. Ministério do Meio Ambiente. (n.d.). A Camada de Ozônio. https://antigo.mma.gov.br/temas/clima,-ozônio-e-desertificação/ozônio.html.

Conselho Federal de Odontologia - CFO. (2015). Regulamento Sobre o Exercício Pelo Cirurgião-Dentista da Prática de Ozonioterapia. https://website.cfo.org.br/wp-content/uploads/2016/01/resolucao-cfo-166-2015.pdf.

Habashneh, R.A., Alsalman, W., \& Khader, Y. (2014). Ozone as an adjunct to conventional nonsurgical therapy in chronic periodontitis: A randomized controlled clinical trial. Journal Of Periodontal Research. 50 (1), 37-43. http://dx.doi.org/10.1111/jre.12177.

Huth, K. C., Quirling, M., Lenzke, S., Paschos, E., Kamereck, K., \& Brand, K. et al. (2011). Effectiveness of ozone against periodontal pathogenic microorganisms. European Journal Of Oral Sciences. 119 (3), 204-210. http://dx.doi.org/10.1111/j.1600-0722.2011.00825.x.

Kaul, R., \& Shilpa, P. S. (2014). Multifaceted ozone and its application in dentistry. Universal Research Journal Of Dentistry. 4 (3), 139-44. http://dx.doi.org/10.4103/2249-9725.140657.

Kumar, A., Bhagawati, S., Tyagi, P., \& Kumar, P. (2014) Current interpretations and scientific rationale of the ozone usage in dentistry: A systematic review of literature. European Journal Of General Dentistry. 3 (3), 175-180. http://dx.doi.org/10.4103/2278-9626.141658.

Landim, R. (2020). 01 Benefícios da acupuntura com ozônio! - Dra. Rose Landim - Saúde com ozônio. YouTube. https://www.youtube.com/watch?v=2o4eyen2ENs.

Libório, K. O. (2020). Ozonioterapia nas Cirurgias da Harmonização Facial - Stand da Philozon no CIOSP. YouTube. https://www.youtube.com/watch?v=GLX-iJZc5d0\&t=739s.

Nesi, A. K. (2018). Ozonioterapia: O uso do ozônio na odontologia. Trabalho de conclusão de curso em odontologia. Porto Velho - RO: Centro Universitário São Lucas.

Nogales, C. G., Ferrari, P. H., Kantorovich, E. O., \& Lage-Marques, J. L. (2008) Ozone Therapy in Medicine and Dentistry. J Contemp Dent Pract .4 (9), 075084 .

Ozônio, Ozonioterapia, Saúde em geral. (n.d.). Os benefícios da ozonioterapia para problemas cardiovasculares. Saúde com ozônio. https://www.saudecomozonio.com.br/os-beneficios-da-ozonioterapia-para-problemas-cardiovasculares/.

Ozônio, Saúde em Geral. (2019). Saiba por que ter um Ozonizador de ar em casa. Dr. Ozônio. https://drozonio3.com.br/2019/03/13/saiba-por-que-ter-umozonizador-de-ar-em-casa/.

Pinheiro, S. L., Silva, C. C., Silva, L. A., Cicotti, M. P., Bueno, C. E. S., Fontana, C. E. et al. (2018). Antimicrobial efficacy of $2.5 \%$ sodium hypochlorite, $2 \%$ chlorhexidine, and ozonated water as irrigants in mesiobuccal root canals with severe curvature of mandibular molars. European Journal Of Dentistry. 12 (01), 94-99. http://dx.doi.org/10.4103/ejd.ejd_324_17.

Saini, R. (2011). Ozone therapy in dentistry: A strategic review. Journal Of Natural Science, Biology And Medicine. 2 (2), 151-124. http://dx.doi.org/10.4103/0976-9668.92318.

Shete, A.V., Subramaniam, A.V., Sable, D. M., Patil, S. V., Mahesh, S. C., Shete, D. M. et al. (2016). Ozone Therapy: healing properties of the blue gas. International Journal Of Oral Health Dentistry. 2 (1), 35-38 http://dx.doi.org/10.5958/2395-499x.2016.00011.3.

Shiva, G., \& Deepa, D. (2016). Applications of ozone therapy in dentistry. Journal Of Oral Research And Review. 8 (2), 86-91. http://dx.doi.org/10.4103/2249-4987.192243.

Shoukheba, M. Y. M., \& Ali, S. A. (2014). The effects of subgingival application of ozonated olive oil gel in patient with localized aggressive periodontitis. A clinical and bacteriological study. Tanta Dental Journal. 11(1), 63-73. http://dx.doi.org/10.1016/j.tdj.2014.04.001.

Srikanth, A., Sathish, M., Venkatanaga, A., \& Harsha. (2013). Application of ozone in the treatment of periodontal disease. Journal Of Pharmacy And Bioallied Sciences. 5(5), 89-94. http://dx.doi.org/10.4103/0975-7406.113304.

Suh, Y., Patel, S., Re, K., Gandhi, J., Joshi, G., \& Smith, N. L. et al. (2019). Clinical utility of ozone therapy in dental and oral medicine. Med Gas Res. 9 (3), 163-167. 